\title{
Real-world impact of reminder packaging on antihypertensive treatment adherence and persistence
}

\section{Leon Dupclay' \\ Michael Eaddy ${ }^{2}$ \\ James Jackson ${ }^{2}$ \\ Aditya Raju \\ Andrew Shim'}

'Novartis Pharmaceuticals, East Hanover, NJ, ${ }^{2}$ Xcenda, Palm Harbor, FL, USA
Correspondence: Michael Eaddy 4I I 4 Woodlands Parkway, Suite 500 Palm Harbor, FL 34685, USA

Tel 727 77| 4126

Fax 727 77। 4I44

Email michael.eaddy@xcenda.com
This article was published in the following Dove Press journal:

Patient Preference and Adherence

13 July 2012

Number of times this article has been viewed

Background: Patient medication adherence is multidimensional and poses significant concerns to health care professionals. One aspect of adherence is a patient forgetting to take their prescribed medication, which may be improved with reminder packaging (RP). The objective of this analysis was to assess the impact of RP on patient adherence to antihypertensive therapy.

Methods: This retrospective, propensity score-matched study evaluated patients switching to a single-pill combination of valsartan-hydrochlorothiazide in RP compared with patients remaining on the combination without reminder packaging (non-RP). Patients receiving combination therapy between April 1, 2009 and July 31, 2010 were eligible for inclusion. Patients were propensity score-matched on baseline adherence and background demographic variables, including comorbidities. Medication possession ratio, proportion of days covered, time to refill, and time to discontinuation were evaluated as primary measures of subsequent adherence and persistence.

Results: In a total of 9266 matched patients (4633 participants in both cohorts), adherence was significantly higher in the RP cohort compared with patients in the non-RP cohort (medication possession ratio, RP $80 \%$ versus non-RP $73 \%$; proportion of days covered, RP $76 \%$ versus non-RP 63\%; both $P<0.001)$. Refill timing was 10 days for RP patients versus 16 days for non-RP patients $(P<0.001)$. Similar trends were observed with respect to time to discontinuation (RP 196 days, non-RP 174 days; $P<0.001$ ). A higher proportion of RP patients remained on therapy compared with non-RP patients, with patients in the RP group being $17 \%$ less likely to discontinue therapy compared with patients in the non-RP group (hazards ratio $0.833 ; 95 \%$ confidence interval 0.793-0.875).

Conclusion: This real-world assessment of differences in adherence and persistence rates demonstrated that patients receiving RP were more adherent and persistent with their treatment regimens.

Keywords: hypertension, reminder packaging, adherence, persistency

\section{Introduction}

Hypertension is an important public health challenge, in which medication and blood pressure control are primary concerns. ${ }^{1,2}$ More importantly, hypertension is a significant risk factor in the development of cardiovascular disease and stroke, which are the leading causes of death in the US.,4 Each year, over 46 million Americans visit physician offices and hospital outpatient and emergency departments with hypertension as their principal diagnosis, and subsequently produce an estimated direct and indirect cost of approximately $\$ 50.6$ billion. ${ }^{5,6}$ Approximately one in three Americans has hypertension, and the disease affects over 76 million people older than 20 years of age. ${ }^{6}$ It is estimated that by 2030, an additional 27 million people could have hypertension, 
which represents a 9.9\% increase in prevalence from $2010 .^{6}$ Although hypertension is a considerable health concern, poor control of high blood pressure is a prevailing trend in the US, with less than $48 \%$ of treated patients having adequate control (<140 mmHg systolic and $90 \mathrm{mmHg}$ diastolic). ${ }^{1,6,7}$

Poor adherence has been cited as the primary reason why patients do not achieve full treatment benefits. ${ }^{8,9}$ This concept also applies to the management of hypertension, because patients have been shown to be noncompliant or do not fully adhere to prescribed treatment regimens. ${ }^{10}$ An earlier study evaluating 8643 patients started on antihypertensive therapies found that only $20 \%$ achieved good levels of adherence, defined as a $\geq 80 \%$ medication possession ratio based on physician's instructions for use. Twenty-one percent of these patients did not fill a second prescription within the 12-month follow-up period. ${ }^{11}$ Similarly, a study evaluating adherence to antihypertensive medications prescribed upon hospital discharge showed that only $54 \%$ of patients were adherent to all of their initial medications at one year. ${ }^{10}$

The implications of nonadherence to antihypertensive medication are well documented. Studies suggest that patients who are adherent to antihypertensive medications are $45 \%$ more likely to achieve blood pressure control and are more likely to attain clinically relevant goals. ${ }^{12,13}$ A 25\% incremental increase in medication adherence has also been associated with a $1.0 \mathrm{mmHg}$ (95\% confidence interval $-1.5,-0.6 \mathrm{mmHg})$ and a $1.2 \mathrm{mmHg}(95 \%$ confidence interval $-1.4,-0.9 \mathrm{mmHg}$ ) reduction in systolic and diastolic blood pressures, respectively, thus contributing to improved antihypertensive treatment outcomes. ${ }^{13}$

Patient adherence in a community setting is associated with various factors that lead to intentional (the patient decides to not take their medication) and unintentional (the patient forgets to take their medication or is careless with the prescribed medication regimen $)^{14}$ behaviors. Such factors that lead to intentional behaviors are the cost of medication, presence of adverse effects, or a lack of understanding of the seriousness of the disease. The existence of one or more intentional, medication-based causal factors considerably increases the risk of patient nonadherence. ${ }^{15}$ Intentional barriers have been traditionally addressed through patient assistance or disease state management programs; however, little emphasis has been placed on methods to address unintentional barriers to patient adherence. ${ }^{16}$ Unintentional nonadherence barriers are often predicted by medication beliefs, chronic disease, and sociodemographics. ${ }^{14}$ At present, very few interventional studies have been conducted to identify patient adherence barriers and match patients to interventions designed to affect these behavioral barriers. ${ }^{16}$ According to a review of patient adherence by Morisky et al, the five most common types of nonadherence with medication are "failing to have a prescription filled", "taking an incomplete dose", "taking the medication at the wrong time", "forgetting to take one or more medications", and "stopping the medication". These nonadherence behaviors require individual consideration in order to develop personalized strategies to improve patient compliance. ${ }^{17,18}$

Adherence-oriented blister packaging may improve treatment adherence and reduce compliance barriers in community and outpatient settings. However, improved packaging has not been used widely and has rarely been studied for medications used to treat chronic or long-term illnesses. ${ }^{19}$ One large-scale epidemiologic analysis comparing the effect of calendar blister packaging with traditional prescription vials on long-term refill behavior found that calendar blister packaging in patients treated with angiotensin-converting enzyme inhibitors was associated with a significantly greater length of treatment and proportion of days covered, but not medication possession ratio. ${ }^{20}$ Further research on medication possession ratio and adherence correlations was deemed necessary. ${ }^{20}$

In October 2009, Novartis Pharmaceuticals distributed the single-pill combination of valsartan-hydrochlorothiazide in reminder packaging (RP) for patients receiving this antihypertensive agent from Walmart pharmacies. Only Walmart pharmacies received valsartan-hydrochlorothiazide in RP. Patients' subsequent refills were switched to RP when their prescriptions of valsartan-hydrochlorothiazide without reminder packaging (non-RP) were depleted. The purpose of this study was to assess the impact of this RP on patient adherence to valsartan-hydrochlorothiazide over a continuous 11-month period. We evaluated the medication possession ratio, proportion of days covered, time to refill, and time to discontinuation as primary measures of adherence and persistence in patients who received the repackaged product compared with patients without RP.

\section{Materials and methods \\ Databases}

Cases of patients receiving the single-pill combination of valsartan-hydrochlorothiazide RP between April 1, 2009 and July 31, 2010 were obtained from the Walmart pharmacy dataset, and controls of patients receiving the single-pill combination of valsartan-hydrochlorothiazide without RP was obtained from the SourceLx (Wolters Kluwer) database. In October 2009, Walmart pharmacies 
began receiving the valsartan-hydrochlorothiazide in RP. Patients' subsequent refills were switched to RP when their non-RP prescriptions of valsartan-hydrochlorothiazide were depleted. The Walmart pharmacy dataset contained information from over 4000 Walmart and Sam's Club pharmacies throughout the US. The Wolters Kluwer database comprised $30 \%$ of the prescription claims filled in the US and accounted for approximately 160 million patient lives. Data elements include demographic variables (age, gender, and geographic region) and essential prescription information for all antihypertensive and nonantihypertensive medications filled during the study period (date of fill, days supply, National Drug Code number, and fill dates of all prescriptions).

Because all pertinent patient information in the databases were encrypted and deidentified, and no patient contact was involved, no informed consent or approval by an institutional review board was required or sought (the data source was fully compliant with the Health Insurance Portability and Accountability).

\section{Sample selection}

Patients were identified in both cohorts and were eligible for analysis if they met all of the following criteria: $\geq 18$ years of age at index prescription date; had at least two hypertension prescriptions in the pre-index and post-index period; did not switch from RP to non-RP; did not receive prescriptions of antihypertensive therapy where days supply was $\geq 90$ days; and did not switch pharmacies. Within the Wolters Kluwer dataset, prescriptions filled by pharmacies outside of the initial pharmacy chain could be included in the patient fill history. Wolters Kluwer identified all patients filling in a pharmacy other than their initial pharmacy affiliations. These patients were subsequently removed to ensure a more valid comparison with Walmart patients. The Walmart database only includes prescriptions filled at Walmart-affiliated pharmacies. Not imposing this criterion would have caused adherence to appear higher for patients in the Wolters Kluwer cohort.

The date of the first antihypertensive therapy (valsartanhydrochlorothiazide combination) received during that period was assigned as the index date (Figure 1). From that date, 6 months of pre-index data and up to 11 months post-index data were collected for all eligible patients. Patients had to have continuous plan enrollment for the 6-month period prior to and at least 11 months following the index date to ensure complete baseline and follow-up information on all patients in the study (Figure 1).

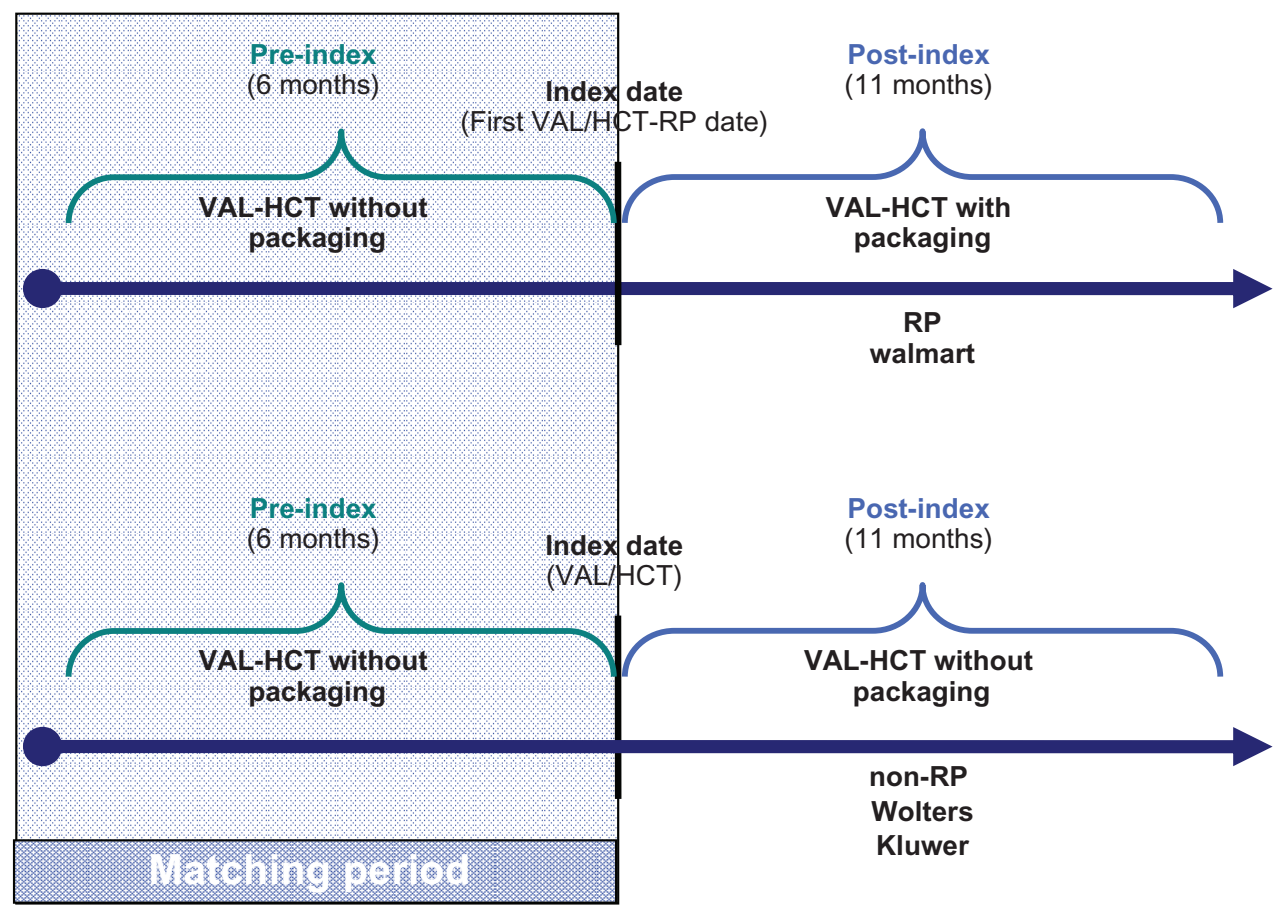

Figure I Study design.

Notes: The index date for first VAL-HCT-RP was defined as the first fill of Diovan ${ }^{\circledR}$ HCT-RP, which occurred after October 28,2009 (the date the packaging was released into the marketplace). The period of time that patients were identified for study inclusion based on their first fill of VAL-HCT-RP was considered as the enrollment period, which ranged from October 28, 2009 through January 3I, 2010, allowing for patients to be followed for 6 months pre-index and post-index Diovan HCT-RP prescription. Abbreviations: RP, reminder packaging; non-RP, without reminder packaging; VAL-HCT, valsartan-hydrochlorothiazide combination. 


\section{Study groups}

RP patients were propensity score-matched to non-RP patients (1:1) on pre-index valsartan-hydrochlorothiazide adherence, the month of their first valsartan-hydrochlorothiazide prescription after October 2009 (the index date), age, gender, number of unique antihypertensive drug classes, number of unique nonantihypertensive prescription classes filled, geographic region, and their chronic disease score (determined by pharmacy claims). Matching was done using the technique of nearest available match on pre-index adherence ( \pm 0.5 units) and estimated propensity score ( \pm 0.001 units). As demonstrated in Table 1, the matching process was successful in creating cohorts with similar demographic and clinical characteristics, with standardized difference values after the match being $<10 \%$ for all baseline characteristics.

\section{Description of RP}

The RP was a blister-packaged container of 30 nonscored valsartan-hydrochlorothiazide combination tablets. As shown in Figure 2, the RP calendar-style container was developed with three rows of 10 tablets. Clear labeling information (days supplied, brand/generic name, storage information, instructions for use) was found on the front of the RP container. A full color photograph of the valsartan-hydrochlorothiazide tablet

Table I Baseline characteristics: after match

\begin{tabular}{|c|c|c|c|c|c|c|}
\hline \multirow{2}{*}{$\begin{array}{l}\text { Characteristics } \\
\text { Demographic characteristics }\end{array}$} & \multicolumn{2}{|c|}{$\begin{array}{l}\text { RP } \\
(n=4633)\end{array}$} & \multicolumn{2}{|c|}{$\begin{array}{l}\text { non-RP } \\
(n=4633)\end{array}$} & \multirow[t]{2}{*}{$P$ value $^{a}$} & \multirow[t]{2}{*}{$\begin{array}{l}\text { Standardized } \\
\text { difference }\end{array}$} \\
\hline & & & & & & \\
\hline Age (mean, SD) & 62.07 & 12.60 & 62.02 & 12.16 & 0.8262 & 0.45 \\
\hline Female (n, \%) & 2900 & 62.59 & 2889 & 62.36 & 0.8250 & 0.49 \\
\hline \multicolumn{7}{|l|}{ Region (n, \%) } \\
\hline Midwest & 849 & 18.33 & 901 & 19.45 & & 2.87 \\
\hline Northeast & 675 & 14.57 & 677 & $|4.6|$ & 0.6556 & 0.12 \\
\hline South & 2711 & 58.52 & 2656 & 57.33 & & 2.40 \\
\hline West & 398 & 8.59 & 399 & 8.61 & & 0.08 \\
\hline \multicolumn{7}{|l|}{ Adherence in pre-index period (mean, SD) } \\
\hline MPR & 82.43 & 18.63 & 82.57 & 19.39 & 0.6910 & 0.77 \\
\hline Refill timing (days) & 8.77 & $|4.6|$ & 8.84 & 13.55 & $0.797 \mid$ & 0.51 \\
\hline \multicolumn{7}{|c|}{ Prescription counts in pre-index period (mean, SD) } \\
\hline Unique HTN Rx classes (n) & 0.62 & 0.79 & 0.62 & 0.79 & 0.8183 & 0.44 \\
\hline Unique HTN Rxs (n) & 0.64 & 0.82 & 0.63 & 0.82 & 0.7718 & 0.55 \\
\hline Unique non-HTN Rx classes (n) & 4.41 & 3.62 & 4.47 & 3.75 & 0.4224 & 1.55 \\
\hline Unique non-HTN Rxs (n) & 4.61 & 3.89 & 4.68 & 4.05 & 0.3072 & 1.97 \\
\hline \multicolumn{7}{|l|}{ Comorbidity in pre-index period } \\
\hline Cardiovascular CDS Ib,c (mean, SD) & 1.38 & 1.69 & 1.37 & 1.67 & 0.8649 & 0.33 \\
\hline Non-cardiovascular CDS II ${ }^{\mathrm{b}, \mathrm{d}}$ (mean, SD) & 2.24 & 2.25 & 2.27 & 2.30 & 0.5337 & 1.25 \\
\hline \multicolumn{7}{|l|}{ Other diseases (n, \%) } \\
\hline Renal disease & 2 & 0.04 & 3 & 0.06 & 1.0000 & 0.93 \\
\hline End-stage renal disease & I & 0.02 & I & 0.02 & 1.0000 & 0.00 \\
\hline Cystic fibrosis & 2 & 0.04 & I & 0.02 & 1.0000 & 1.20 \\
\hline Liver failure & 7 & 0.15 & 9 & 0.19 & 0.8036 & 1.04 \\
\hline Transplantation & 0 & 0.00 & I & 0.02 & - & - \\
\hline Thyroid disorders & 587 & 12.67 & 592 & 12.78 & 0.8987 & 0.32 \\
\hline Pain and inflammation & 837 & 18.07 & 828 & 17.87 & 0.8180 & 0.51 \\
\hline Pain & 1020 & 22.02 & 1009 & 21.78 & 0.7957 & 0.57 \\
\hline Depression & 928 & 20.03 & 911 & 19.66 & 0.6730 & 0.92 \\
\hline Psychotic illness & 78 & 1.68 & 84 & 1.81 & 0.6771 & 0.99 \\
\hline Bipolar disorder & 4 & 0.09 & 3 & 0.06 & 1.0000 & 0.79 \\
\hline Human immunodeficiency virus & 114 & 2.46 & 102 & 2.20 & 0.4368 & 1.72 \\
\hline Anxiety and tension & 613 & 13.23 & 565 & 12.20 & 0.1094 & 3.11 \\
\hline
\end{tabular}

Notes: ${ }^{a}$ t-test for continuous variables and Chi-square test for categorical variables; ${ }^{b} \mathrm{CDS}$ is calculated by assigning a weight (score) to each drug class to correspond to disease complexity and severity. It is an aggregate of the assigned weights based on medication use, but not on frequency of use; 'CDS I is derived based on hypertensive (excluding valsartan-hydrochlorothiazide claims) and cardiac medications, by assigning scores suggested by Von Korff et al. ${ }^{21}$ Range (0-7); ${ }^{\mathrm{d} C D S ~ I I ~ i s ~ d e r i v e d ~ b a s e d ~ o n ~}$ medications of epilepsy, tuberculosis, rheumatologic conditions, hyperlipidemia, malignancies, Parkinson's disease, diabetes, glaucoma, ulcer, respiratory illness, gout, acne, migraines, Crohn's disease, and coronary disease by assigning scores suggested by Von Kroff et al. ${ }^{21}$ Range $(0-27)$ Standardized difference $\left.=\mid 00 *(x I-x 2) / \sqrt{ }(\mathbf{s} I 2+s 22) / 2\right\}$, where $x \mid=$ mean of group $1, x 2=$ mean of group $2, s \mid=$ standard deviation of group 1 , and $s 2=$ standard deviation of group 2 .

Abbreviations: CDS, chronic disease score; ESRD, end-stage renal disease; HIV, human immunodeficiency virus; HTN, hypertension; MPR, medication possession ratio; $\mathrm{RP}$, reminder packaging; Rx, prescription; SD, standard deviation; non-RP, without reminder packaging. 

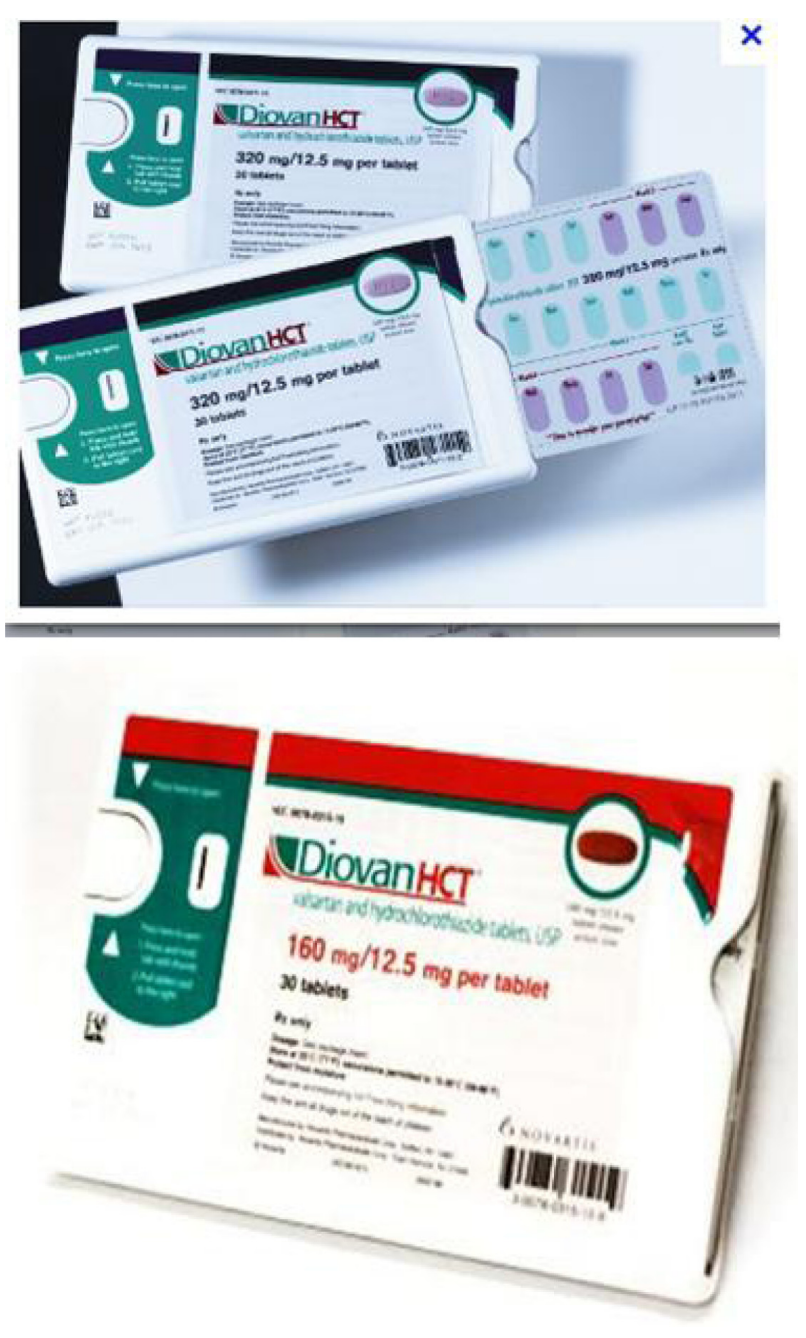

Figure 2 Reminder packaging dispensed to patients.

was provided on the cover for easy recognition. Instructions on how to open the RP were printed on the outside container cover. A reminder to reorder was found inside the blister card insert to prompt the reordering of refills by patients at the end of each monthly regimen.

\section{Measures}

To determine if RP improved adherence and persistence, the following outcomes of interest were assessed: medication possession ratio, time to refill, proportion of days covered, and time to discontinuation. Because this dataset did not contain medical claims information, measures could not be adjusted for hospitalizations. Such factors were assumed to be equivalent across cohorts.

\section{Medication possession ratio}

Medication possession ratio evaluated both medication skipping and stopping between the first and last observed prescription. This measure is more appropriate when there is an increased likelihood that all prescriptions filled for a medication may not exist in a database, or that discontinuation of a prescription is likely because of a physician order. It was calculated as the ratio of days supply of medication to total number of days between the first and last prescriptions. Patients who consistently refilled early and may have had medication possession ratio values $>100 \%$ were deemed to have a medication possession ratio value of $100 \%$.

\section{Proportion of days covered}

Proportion of days covered was a composite measure that evaluated both medication skipping and stopping. It was calculated as the ratio of days supply of medication to total number of days in the follow-up period (11 months). Patients who consistently refilled early and may have had proportion of days covered values $>100 \%$ were deemed to have a proportion of days covered value of $100 \%$.

\section{Time to discontinuation}

Patient length of therapy or time to discontinuation measured continuous treatment without prolonged gaps in therapy. Patients were deemed to have discontinued therapy when more than 30 days had elapsed without a prescription refill. A patient's length of therapy was calculated from the index date to the expected end date of the last prescription prior to discontinuing therapy.

\section{Time to refill}

Based on the above methods, the time between successive refills of relevant medications was calculated. The mean time to refill was calculated using all prescriptions within the defined analysis period. Adherence and persistence outcomes were initially assessed over the 6-month post-index period, with a subsequent 11-month validation analysis completed to assess stability of adherence and persistence over a longer duration of time. Given the similarity of the results, only the 11-month data are presented within the context of this paper.

\section{Statistical analysis}

Before-match baseline characteristics were compared using $t$-tests for continuous variables and Chi-square tests for categorical variables. After-match continuous variables were compared using paired $t$-tests, and categorical variables were compared using McNemar's test, with an a priori level of significance of alpha $=0.05$. Differences in time to discontinuation were assessed utilizing Cox proportional 
hazards model. All analyses were performed using SAS version 9.2 (SAS, Cary, NC).

\section{Results}

A total of 9266 matched patients were included in the analysis (4633 in both RP and non-RP groups). Following cohort matching, the baseline characteristics for the comparison groups were well balanced, and after-match standardized differences were $<10 \%$ for all baseline characteristics (Table 1). The mean age (standard deviation) of the sample was 62 years and was predominantly female in both cohorts $(62 \%)$.

With similar baseline adherence (medication possession ratio $82 \%$ ), the post-index adherence was significantly higher in the RP cohort (patients who switched from valsartan-hydrochlorothiazide combination therapy without RP to valsartan-hydrochlorothiazide combination therapy with RP) compared with the non-RP cohort (valsartanhydrochlorothiazide combination patients who did not switch to $\mathrm{RP}$, medication possession ratio $80 \%$ for $\mathrm{RP}$ cohort versus $73 \%$ for the non-RP cohort; proportion of days covered $76 \%$ for RP group versus $63 \%$ for non-RP group; both $P<0.001$, Table 2).

The refill timing was 10 days for RP patients versus 16 days for non-RP patients $(P<0.001)$. Similar trends were observed with respect to time to discontinuation (196 days for RP patients versus 174 days for non-RP patients; $P<0.001$ ), with a higher proportion of patients in the RP cohort remaining on therapy compared with the non-RP cohort (34\% versus 30\%; $P<0.001$ respectively, Figure 3). Survival analysis indicated that patients in the RP cohort were $17 \%$ less likely to discontinue therapy compared with patients in the non-RP cohort (hazards ratio 0.833; confidence interval 0.79-0.875). When evaluating

Table 2 Adherence and persistency outcomes

\begin{tabular}{|c|c|c|c|c|c|}
\hline \multirow[t]{2}{*}{ Outcome } & \multicolumn{2}{|c|}{$\begin{array}{l}\text { RP } \\
(n=4633)\end{array}$} & \multicolumn{2}{|c|}{$\begin{array}{l}\text { non-RP } \\
(n=4633)\end{array}$} & \multirow[t]{2}{*}{$P$ value $^{a}$} \\
\hline & Mean & SD & Mean & SD & \\
\hline \multicolumn{6}{|l|}{ Adherence (mean, SD) } \\
\hline MPR & 79.6 & $(18.7)$ & 73.2 & $(21.3)$ & $<0.000$ I \\
\hline PDC & 65.2 & $(26.2)$ & 62.7 & $(25.1)$ & $<0.000$ I \\
\hline \multicolumn{6}{|l|}{ Persistence (mean, SD) } \\
\hline $\begin{array}{l}\text { Time to discontinuation } \\
\text { (days) }\end{array}$ & 195.9 & $(I 15.8)$ & 174.0 & $(|| 18.6)$ & $<0.0001$ \\
\hline Refill timing (days) & 10.4 & $(16.5)$ & 15.6 & $(20.0)$ & $<0.0001$ \\
\hline
\end{tabular}

Notes: Refill timing: time between successive refills of valsartan-hydrochlorothiazide. aPaired $t$-test. Matching was based on propensity scores.

Abbreviations: MPR, medication possession ratio; PDC, proportion of days covered; RP, reminder packaging; SD, standard deviation; non-RP, without reminder packaging. adherence rates after stratifying by pre-index medication possession ratio categories, the medication possession ratio was higher in the post-index period for both cohorts when the pre-index medication possession ratio was between $0 \%$ and 59\%. Compared with non-RP patients, the RP patients with a pre-index medication possession ratio between $20 \%$ and $79 \%$ showed a greater improvement in pre-index to postindex medication possession ratio values (Table 3 ). In the highest medication possession ratio category $(80 \%-100 \%)$, the reduction in mean pre-index and post-index medication possession ratio values was less in the RP cohort $(10.55 \%)$ than in non-RP cohort $(16.5 \% ; P=0.0001$ for pre- and post differences between cohorts, Table 3 ).

\section{Discussion}

Patient adherence is a principal concern in comprehensive patient care. Nonadherence is a primary reason why full treatment benefits are not realized. ${ }^{8}$ In addition to the clinical ramifications, it is estimated that the overall cost of medication nonadherence ranges from $\$ 100$ billion to $\$ 300$ billion per year, further quantifying the problem of nonadherence. ${ }^{22}$ Increasing patient adherence patterns will have a substantial impact on medical treatment outcomes. ${ }^{23}$ Our analysis demonstrates the potential impact of adherence-aiding strategies, such as RP and reminder calendar packaging, on patient adherence. This large, propensity-matched sample demonstrated that patients on an antihypertensive regimen (an angiotensin receptor blocker-hydrochlorothiazide combination) showed consistent improvement in adherence and persistence through the use of RP. Our research represents one of the first real-world studies to evaluate the role of RP on adherence and persistence in single-pill combination antihypertensive therapy. This research could lead to further advances in antihypertensive packaging, smart packaging, and patient reminder systems. Enhancements in dosing instructions or an increased amount of space allocated on the outside of packaging may also accompany RP efforts to promote greater patient education and improve adherence.

Previous research comparing calendar blister packaging with traditional prescription bottles in patients with cardiovascular disease and hypertension has shown similar medication adherence benefits. ${ }^{10,19,20,24,25}$ A systematic review of 10 randomized controlled trials showed that calendar RP combined with education and other reminder strategies may lead to improved adherence. ${ }^{24} \mathrm{~A}$ recent meta-analysis assessing the effect of RP on blood pressure measurements found that RP significantly decreased diastolic blood pressure (mean difference $5.89 \mathrm{mmHg}$; 95\% confidence 


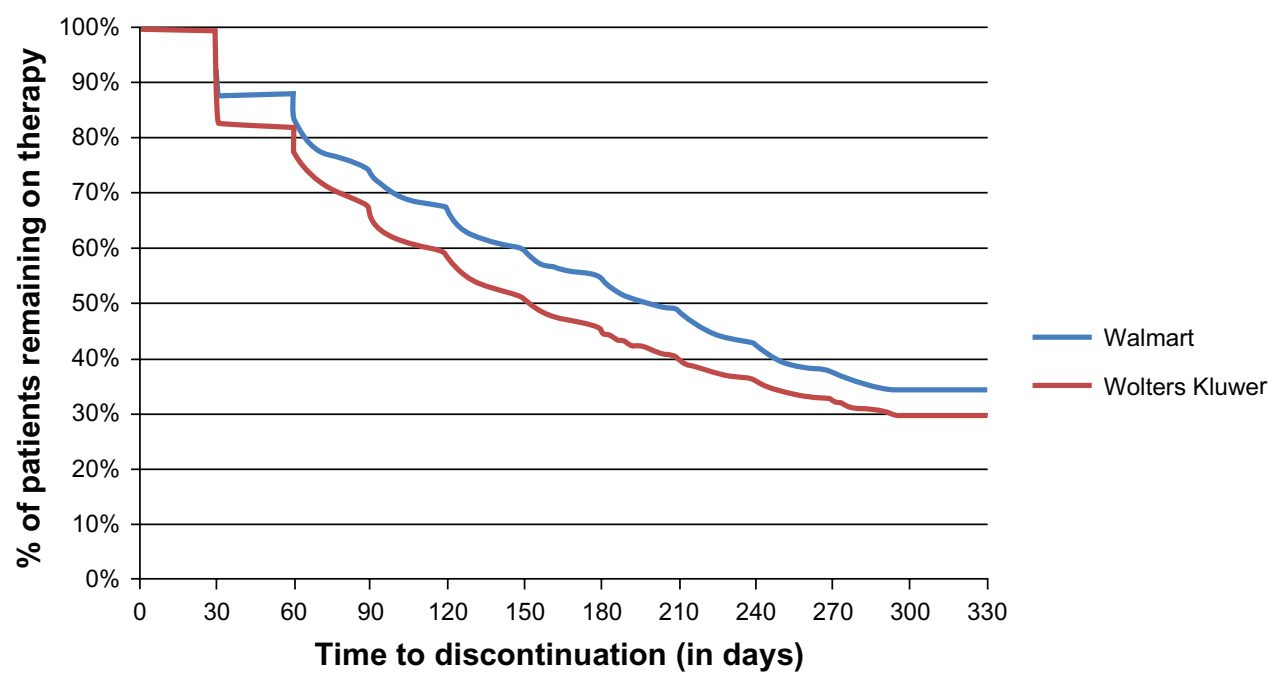

Figure 3 Time-to-event (treatment discontinuation) analysis.

interval $-6.70,-5.09 ; P<0.00001)$. This study also found the presence of a RP aid was preferred by patients with low literacy levels. ${ }^{26}$ However, high-quality studies of adequate size and duration in the real world are still needed to assess the clinical effectiveness of RP interventions in therapy further. The use of technology in adherence, such as phone call reminders, electronic medication reconciliation, text messages, interactive voice responses, and programmed electronic audiovisual reminders, is evolving and requires further assessment. These technologic advances may be beneficial when combined with RP and be more practical adherence-modifying strategies..$^{27,28}$

The clinical effectiveness of calendar RP may be greatest in patients who are most likely to forget, such as the elderly.
Supporting this premise are studies showing that medication packaging improved adherence and treatment outcomes in older ambulatory patients and improved the rate of successful self-medication. ${ }^{19,29}$ Elderly patients ( $\geq 81$ years) receiving daily-dose blister packaging (pill calendar) refilled their prescriptions more often $(P=0.01)$, had higher medication possession ratios $(P=0.04)$, and lower diastolic blood pressure $(P=0.01)$ than patients who used traditional bottles. ${ }^{19}$ Additionally, blister packaging and RP may ease the difficulty of accessing medication, as shown in a study which reported that $10 \%$ of patients using blister packaging were unable to access their medication, compared with $14 \%$ of patients using a screwcap bottle, and $32 \%$ of patients using a bottle with a snap lid. ${ }^{30}$ RP strategies that seek to assist elderly

Table 3 Outcomes stratified by pre-index medication possession ratio categories

\begin{tabular}{|c|c|c|c|c|c|c|c|c|c|c|c|}
\hline \multirow{3}{*}{$\begin{array}{l}\text { Pre-period MPR } \\
\text { categories (\%) }\end{array}$} & \multicolumn{5}{|l|}{$\mathbf{R P}$} & \multicolumn{5}{|c|}{ non-RP } & \multirow[t]{3}{*}{$P$ value $^{\mathrm{a}}$} \\
\hline & \multicolumn{3}{|c|}{$\begin{array}{l}\text { Pre-period } \\
(n=4633)\end{array}$} & \multicolumn{2}{|c|}{$\begin{array}{l}\text { Post-period } \\
(n=4633)\end{array}$} & \multicolumn{3}{|c|}{$\begin{array}{l}\text { Pre-period } \\
(n=4633)\end{array}$} & \multicolumn{2}{|c|}{$\begin{array}{l}\text { Post-period } \\
(n=4633)\end{array}$} & \\
\hline & $n$ & Mean & SD & Mean & SD & $n$ & Mean & SD & Mean & SD & \\
\hline \multicolumn{12}{|l|}{$\overline{M P R}$} \\
\hline $0-19$ & 3 & 10.89 & $(7.58)$ & 58.73 & $(26.88)$ & 2 & 4.83 & $(0.16)$ & 41.21 & $(8.36)$ & 0.6105 \\
\hline $20-39$ & 144 & 30.76 & $(5.52)$ & $62.24 *$ & $(21.07)$ & 153 & 34.29 & $(4.06)$ & $57.32 *$ & $(19.66)$ & 0.0008 \\
\hline $40-59$ & 466 & 50.20 & $(5.18)$ & $66.31 *$ & $(20.66)$ & 584 & 50.28 & $(5.29)$ & $60.84 *$ & $(20.46)$ & 0.0001 \\
\hline $60-79$ & 1098 & 70.92 & $(5.32)$ & $76.18 *$ & (18.93) & 905 & 70.23 & $(5.83)$ & $66.12 *$ & $(20.15)$ & 0.0001 \\
\hline $80-100$ & 2922 & 94.51 & $(5.98)$ & $83.95 *$ & $(16.18)$ & 2989 & 95.15 & $(5.90)$ & $78.65^{*}$ & (19.74) & 0.0001 \\
\hline \multicolumn{12}{|l|}{ Refill timing (days) } \\
\hline $0-19$ & 3 & 93.67 & $(29.57)$ & 27.37 & $(21.82)$ & 2 & 88.00 & $(16.97)$ & 43.33 & $(15.08)$ & 0.6118 \\
\hline $20-39$ & 144 & 67.76 & $(19.56)$ & $24.52 *$ & $(24.52)$ & 153 & 56.25 & (II.84) & $0.12 *$ & $(23.10)$ & 0.0001 \\
\hline $40-59$ & 466 & 29.33 & $(6.56)$ & $20.40 *$ & (21.57) & 584 & 29.08 & $(6.69)$ & $25.17^{*}$ & (22.75) & 0.0004 \\
\hline $60-79$ & 1098 & 11.69 & $(3.40)$ & 12.48 & $(17.42)$ & 905 & 12.32 & $(4.22)$ & $20.31 *$ & (20.7I) & 0.0001 \\
\hline $80-100$ & 2922 & 1.40 & $(2.00)$ & $7.35^{*}$ & (13.36) & 2989 & 1.36 & $(2.06)$ & $11.61 *$ & (17.73) & 0.0001 \\
\hline
\end{tabular}

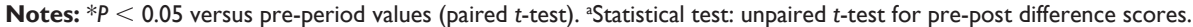

Abbreviations: MPR, medication possession ratio; non-RP, without reminder packaging; RP, reminder packaging; SD, standard deviation. 
patients in managing various types of prescription bottles and to prevent potential adherence barriers could widely improve adherence and corresponding clinical outcomes.

Although RP strategies may achieve improvement in adherence rates and clinically relevant outcomes, there are limited data on the cost-effectiveness of RP in general practice or with combination antihypertensive therapies such as valsartan-hydrochlorothiazide. Skaer et al found that use of a calendar pill organizer for hypertension achieved a $\$ 13.55$ decrease in adjusted mean annual total health care costs per patient, which implies the potential for cost savings. ${ }^{31}$ A review of relative cost-effectiveness and adherence interventions found that, on average, the cost of customized medication unit-of-use packaging for 6 months was $\$ 24.76$ per patient and resulted in a relative improvement in adherence of 1.17-1.20 over the control group. ${ }^{32,33}$ In addition, increased adherence resulted in longer-term savings in the overall costs of treating cardiovascular disease and related conditions. ${ }^{32,33}$ An evaluation of the impact of medication adherence on health care utilization and costs for hypertension and other cardiovascular disease-related conditions suggests that increased drug utilization is driven by improved adherence. ${ }^{34}$ Sokol et al found that all-cause hospitalization rates were lowest for patients with hypertension who had the highest level of medication adherence. The average return on investment for a $20 \%$ increase in drug utilization was $4.0 .{ }^{34}$

Although the evidence highlighting the value of RP in our study was very positive, there are limitations that should be considered. As with any retrospective study, selection bias may confound the relationship between treatment and the outcomes of interest. ${ }^{35}$ To minimize this bias, propensity score matching was used, controlling for a host of demographic and comorbidity measures, as well as baseline adherence. However, due to the nonrandomized nature of the study, propensity matching may not be able to balance unmeasured confounders. Additionally, the unavailability of medical data precluded the evaluation of comorbidities, disease severity, specific disease diagnoses, and hospitalizations.

Even with the aforementioned limitations, few studies have assessed the impact of RP on medications used to treat chronic conditions. Our study demonstrates that RP in the subgroup of patients on single-pill combination antihypertensive therapy has a tremendously positive impact. Although intentional nonadherence is a primary factor in patient failure to achieve treatment outcomes, efforts can be made to address unintentional patient compliance barriers. Unintentional barriers to compliance continue to affect treatment paradigms and often go unnoticed or are rarely addressed. Forgetting to take a medication is a common adherence issue in elderly patients and is attributed to such factors as using more than one pharmacy, seeing multiple physicians, confusion regarding the treatment regimen, mislabeling of containers, and inability to open childproof containers. ${ }^{18} \mathrm{RP}$ is a tool to improve unintentional barriers associated with patient compliance in all patient groups, and especially in elderly populations. The ease of use of reminder daily-dose blister packaging offers multiple patient benefits compared with traditional bottles and loose tablets. The use of this patient-friendly packaging has significant effects on adherence and persistence.

\section{Conclusion}

This real-world assessment of differences in adherence and persistence in treated hypertensive patients who switched to RP therapy compared with those who did not indicates that patients receiving RP were more adherent and persistent in their treatment regimens. Improvements in adherence were assessed by increases in medication possession ratio and proportion of days covered. An increase in persistence was measured by shorter gaps between successive refills in the RP cohort over an 11-month period. These findings were also consistent when the analysis was stratified by baseline levels of adherence. This matched patient analysis successfully demonstrates the positive effect of RP on antihypertensive therapy adherence and persistence rates.

\section{Acknowledgment}

We thank Fred Amberger, Novartis Pharmaceuticals, for his assistance with editorial review.

\section{Disclosure}

Research funded by Novartis Pharmaceuticals, East Hanover, NJ.

\section{References}

1. Kearney PM, Whelton M, Reynolds K, Whelton PK, He J. Worldwide prevalence of hypertension: a systematic review. J Hypertens. 2004; 22(1):11-19.

2. Kearney PM, Whelton M, Reynolds K, Muntner P, Whelton PK, He J. Global burden of hypertension: analysis of worldwide data. Lancet. 2005;365(9455):217-223.

3. Kochanek KD, Xu JQ, Murphy SL, et al. Deaths: preliminary data for 2009. Natl Vital Stat Rep. 2011;59(4):1-51.

4. Centers for Disease Control and Prevention. High Blood Pressure Fact Sheet. December, 2011. Available from: http://www.cdc.gov/DHDSP/ data_statistics/fact_sheets/docs/fs_bloodpressure.pdf. Accessed May 8, 2012 .

5. National Center for Health Statistics. Health, United States, 2010: With special feature on death and dying. Hyattsville, MD. 2011. Available from: http://www.cdc.gov/nchs/data/hus/hus10.pdf. Accessed May 8, 2012. 
6. Roger VL, Go AS, Lloyd-Jones DM, et al. Heart disease and stroke statistics - 2012 update: a report from the American Heart Association. Circulation. 2012;125(1):188-197.

7. Hajjar I, Kotchen TA. Trends in prevalence, awareness, treatment, and control of hypertension in the United States, 1988-2000. JAMA. 2003;290(2):199-206.

8. Golay A. Pharmacoeconomic aspects of poor adherence: can better adherence reduce healthcare costs? J Med Econ. 2011;14(5):594-608.

9. World Health Organization Report. Adherence to long-term therapies project. Evidence for action. Available from: http://whqlibdoc.who.int/ publications/2003/9241545992.pdf. Accessed April 1, 2012.

10. Kulkarni SP, Alexander KP, Lytle B, Heiss G, Peterson ED. Longterm adherence with cardiovascular drug regimens. Am Heart J. 2006;151(1):185-191.

11. Monane M, Bohn RL, Gurwitz JH, et al. The effects of initial drug choice and comorbidity on antihypertensive therapy compliance: results from a population-based study in the elderly. Am J Hypertens. 1997;10(7):697-704.

12. Bramley TJ, Gerbino PP, Nightengale BS, Frech-Tamas F. Relationship of blood pressure control to adherence with antihypertensive monotherapy in 13 managed care organizations. J Manag Care Pharm. 2006;12(3):239-245.

13. Ho PM, Rumsfeld JS, Masoudi FA, et al. Effect of medication nonadherence on hospitalization and mortality among patients with diabetes mellitus. Arch Intern Med. 2006;166(17):1836-1841.

14. Gadkari AS, McHorney CA. Unintentional non-adherence to chronic prescription medications: how unintentional is it really? BMC Health Serv Res. 2012;12(1):98.

15. Wilke T, Müller S, Morisky DE. Toward identifying the causes and combinations of causes increasing the risks of nonadherence to medical regimens: combined results of two German self-report surveys. Value Health. 2011;14(8):1092-1100.

16. Touchette D, Shipiro N. Medication compliance, adherence, and persistence: current status of behavioral and educational interventions to improve outcomes. J Manag Care Pharm. 2008;14(6):S2-S10.

17. Morisky DE, Green LW, Levine DM. Concurrent and predictive validity of a self-reported measure of medication adherence. Med Care. 1986;24(1):67-74

18. Morisky, D. Adherence or compliance behavior. Encyclopedia of Public Health, 2002. Available from: http://www.enotes.com/adherencecompliance-behavior-reference/adherence-compliance-behavior. Accessed May 8, 2012.

19. Schneider PJ, Murphy JE, Pedersen CA. Impact of medication packaging on adherence and treatment outcomes in older ambulatory patients. J Am Pharm Assoc. 2008;48(1):58-63.

20. Zedler BK, Joyce A, Murrelle L, Kakad P, Harpe SE. A pharmacoepidemiologic analysis of the impact of calendar packaging on adherence to self-administered medications for long-term use. Clin Ther. 2011;33(5):581-597.
21. Von Korff M, Wagner EH, Saunders K. A chronic disease score from automated pharmacy data. J Clin Epidemiol. 1992;45:197.

22. Dezii CM. Medication noncompliance: what is the problem? Manag Care. 2000;Supp1 9:7-12.

23. World Health Organization Report. Noncommunicable diseases and mental health adherence to long-term therapies project, 2003. Available from: http://whqlibdoc.who.int/publications/2003/9241545992.pdf. Accessed May 8, 2012.

24. Zedler BK, Kakad P, Colilla S, Murrelle L, Shah NR. Does packaging with a calendar feature improve adherence to self-administered medication for long-term use? A systematic review. Clin Ther. 2011; 33(1):62-73

25. Lee JK, Grace KA, Taylor AJ. Effect of a pharmacy care program on medication adherence and persistence, blood pressure, and lowdensity lipoprotein cholesterol: a randomized controlled trial. JAMA 2006;296(21):2563-2571.

26. Mahtani KR, Heneghan CJ, Glasziou PP, Perera R. Reminder packaging for improving adherence to self-administered long-term medications. Cochrane Database Syst Rev. 2011;9:CD005025.

27. Fenerty SD, West C, Davis SA, et al. The effect of reminder systems on patients' adherence to treatment. Patient Prefer Adherence. 2012;6:127-135.

28. Granger BB, Bosworth HB. Medication adherence: emerging use of technology. Curr Opin Cardiol. 2011;26(4):279-287.

29. Ware GJ, Holford NH, Davison JG, Harris RG. Unit dose calendar packaging and elderly patient compliance. N Z Med J. 1991;104(924): 495-497.

30. Beckman A, Bernsten C, Parker MG, Thorslund M, Fastbom J. The difficulty of opening medicine containers in old age: a population-based study. Pharm World Sci. 2005;27(5):393-398.

31. Skaer TL, Sclar DA, Markowski DJ, Won JK. Effect of value-added utilities on prescription refill compliance and health care expenditures for hypertension. J Hum Hypertens. 1993;7(5):515-518.

32. Sclar DA, Skaer TL, Robison LM, et al. Effect of antihypertensive formulation on health service expenditures. Clin Auton Res. 1993;3(6): 363-368.

33. Chapman RH, Ferrufino CP, Kowal SL, et al. The cost and effectiveness of adherence-improving interventions for antihypertensive and lipidlowering drugs. Int J Clin Pract. 2010;64(2):169-181.

34. Sokol MC, McGuigan KA, Verbrugge RR, Epstein RS. Impact of medication adherence on hospitalization risk and healthcare cost. Med Care. 2005;43(6):521-530.

35. Harpe SE. Using secondary data sources for pharmacoepidemiology and outcomes research. Pharmacotherapy. 2009;2992:138-153.
Patient Preference and Adherence

\section{Publish your work in this journal}

Patient Preference and Adherence is an international, peer-reviewed, open access journal focusing on the growing importance of patient preference and adherence throughout the therapeutic continuum. Patient satisfaction, acceptability, quality of life, compliance, persistence and their role in developing new therapeutic modalities and compounds to

\section{Dovepress}

optimize clinical outcomes for existing disease states are major areas of interest. This journal has been accepted for indexing on PubMed Central. The manuscript management system is completely online and includes a very quick and fair peer-review system. Visit http://www.dovepress.com/ testimonials.php to read real quotes from published authors. 